\title{
LATENT THERMAL ENERGY STORAGE FOR SOLAR DRIVEN COOLING SYSTEMS
}

\author{
Kristina Lebedeva, Lana Migla \\ Riga Technical University, Latvia \\ kristina.lebedeva@rtu.lv, lana.migla@rtu.lv
}

\begin{abstract}
The paper presents a study based on the transition to a low carbon economy, the targets of at least $27 \%$ of RES, together with the proposed $30 \%$ target on energy efficiency and at least $40 \%$ reduction in greenhouse gas emissions by 2030 will be key drivers in achieving the EU policy goals. According to information provided by the International Energy Agency (IEA), the energy demand for cooling is the fastest growing end-use in the building sector. Sales are rising three times faster than efficiency improvements, and 10 air conditioners will be sold every second over the next 30 years. IEA gives an energy use for space cooling of 3.5 EJ per year and forecasts a more than twice as high demand of 9 EJ per year in $2050.84 \%$ of heating and cooling is still generated from fossil fuels, while only $16 \%$ is generated from renewable energy. In order to fulfil the EU's climate and energy goals, the heating and cooling sector must sharply reduce its energy consumption and cut its use of fossil fuels. Solar cooling may have a very positive environmental impact reducing the usage of fossil fuels. The benefit could be evaluated by the avoided amount of $\mathrm{CO} 2$ emission, which can reach about 0.5 $1.0 \mathrm{kgCO} 2 \cdot \mathrm{kWh}^{-1}$ for the grid electricity according to different mixing in electricity production for various countries. Then for every $\mathrm{kWh}$ of cooling produced by solar energy, an amount of $\mathrm{CO} 2$ that avoided is in the range 160-330 gCO2. In recent years, interest in solar cooling systems has increased in the world and in Europe. Solar Cooling Systems (SCS) are coming solutions to cover the rising demand of air-conditioning. Due to its potential to reduce greenhouse gas emissions, solar driven systems are included in the IEA Solar Heating and Cooling Strategic Plan Key Technologies. The main aim of the paper is to investigate and validate a solar thermal storage tank loaded with 20 cylindrical vertical tubes filled with PCM. The study of a solar thermal driven air-conditioning system with possibility of integration latent heat storage in the cooling system is presented. A simulation model for system dynamical simulations was developed. The PCM melting process and its impact on stable heat maintenance was analyzed in deep. It was concluded that using the PCM storage tank, the cooling system COP on average increased comparing COP of SCS without a PCM storage tank. It is concluded that: auxiliary heater turns on times decreased by $21 \%$ compared to usual SCS. The use of latent heat storage technology in the solar cooling system will reduce $\mathrm{CO} 2$ emissions by $5-7 \%$.
\end{abstract}

Keywords: latent thermal energy storage, solar driven cooling, PCM.

\section{Introduction}

In recent years, interest in solar cooling systems has increased in the world and in Europe [1;2]. Solar Cooling Systems (SCS) are a promising solution to cover the rising demand for cooling. Due to the potential to reduce greenhouse gas emissions, solar driven systems are included in the International Energy Agency Solar Heating and Cooling Strategic Plan Key Technologies. One of the major drawbacks of solar energy is that energy is not fully consumed, when it occurs, that is why the energy storage options should be used.

One of the main factors that increase indoor temperature, is solar radiation passing through building envelop requiring cooling of rooms, consuming a lot of energy, but in the evenings, when the rooms are heated, solar energy should be used for energy-saving solutions. The study proposed an innovative technological solution that would improve solar energy technology. The development of technology for cold production and latent heat storage, what does not only reduce losses, increases the efficiency of the solar system, but also prolongs the storage time of stored energy and reduces fossil fuel consumption, will decline following the amount of $\mathrm{CO}_{2}$ emissions. According to published information, the number of solar cooling systems installed worldwide is estimated to be around 1200 [3]. Most of these systems are single stage absorption chillers using water as the working fluid [4] and only a small part of them use the options of latent heat storage.

Based on the previous research on solar cooling system use in Latvia, the possibility of using phase change materials for latent heat storage will be considered in the paper. The paper presents a study of a solar thermal driven air-conditioning system with possibility of integration latent heat storage in the cooling system. A simulation model will be developed for system dynamical simulations. 


\section{Materials and methods}

After literature review [5-9], it was decided to increase the efficiency of SCS by latent thermal energy storage. The various storage tank structures were examined in detail, considered the parameters of an existing SCS, it was decided to adapt the existing storage tank.

A new design was developed - in the existing storage tank 20 cylindrical vertical tubes filled with PCM would be placed. The developed configuration is described below.

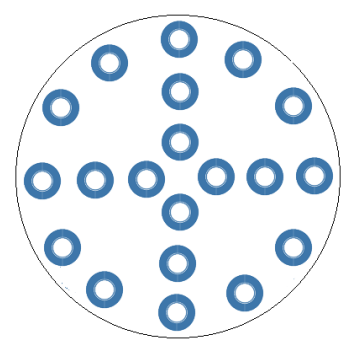

Fig. 1. Modified storage tank section with 20 cylindrical vertical tubes

Based on previous experience working with PCM, the paraffin from a previously known producer was selected for this study. Considering the product data sheet, the more suitable PCM was selected RT70HC. The cylindrical vertical tubes were filled with PCM and tested. In order to verify the functioning of the system, mathematical modeling was developed. The theoretical mathematical calculations show results close to practical measuring. After validation, the simulation model was developed for SCS dynamical simulations. The configuration of the vertical tubes: the inner tube diameter is $25 \mathrm{~mm}$ with $1.2 \mathrm{~mm}$ thickness and the outer tube diameter is $100 \mathrm{~mm}$ with $2 \mathrm{~mm}$ thickness with lengths $500 \mathrm{~mm}$, all pipes are made from copper to ensure high thermal conductivity and to enhance heat transfer between PCM and the heat transfer fluid (water).

The model was adapted to the model with low-power heat driven adsorption cooling. Adsorption chiller nominal power is $8 \mathrm{~kW}$ and maximal cooling capacity is $11 \mathrm{~kW}$. Heat was used for thermal driving chilling; this heat was mainly derived from the solar thermal system. In this case, the solar thermal system with thermal power $15 \mathrm{~kW}$ at $\Delta T=70 \mathrm{~K}$ was used [10]. One cubic meter storage tank with $8 \mathrm{~kW}$ electric heater is included in the solar thermal system. After calculations and research literature review [5-8; 11], it was decided to modify the storage tank so that it could be loaded with 20 cylindrical vertical tubes filled with PCM (see Fig. 2).

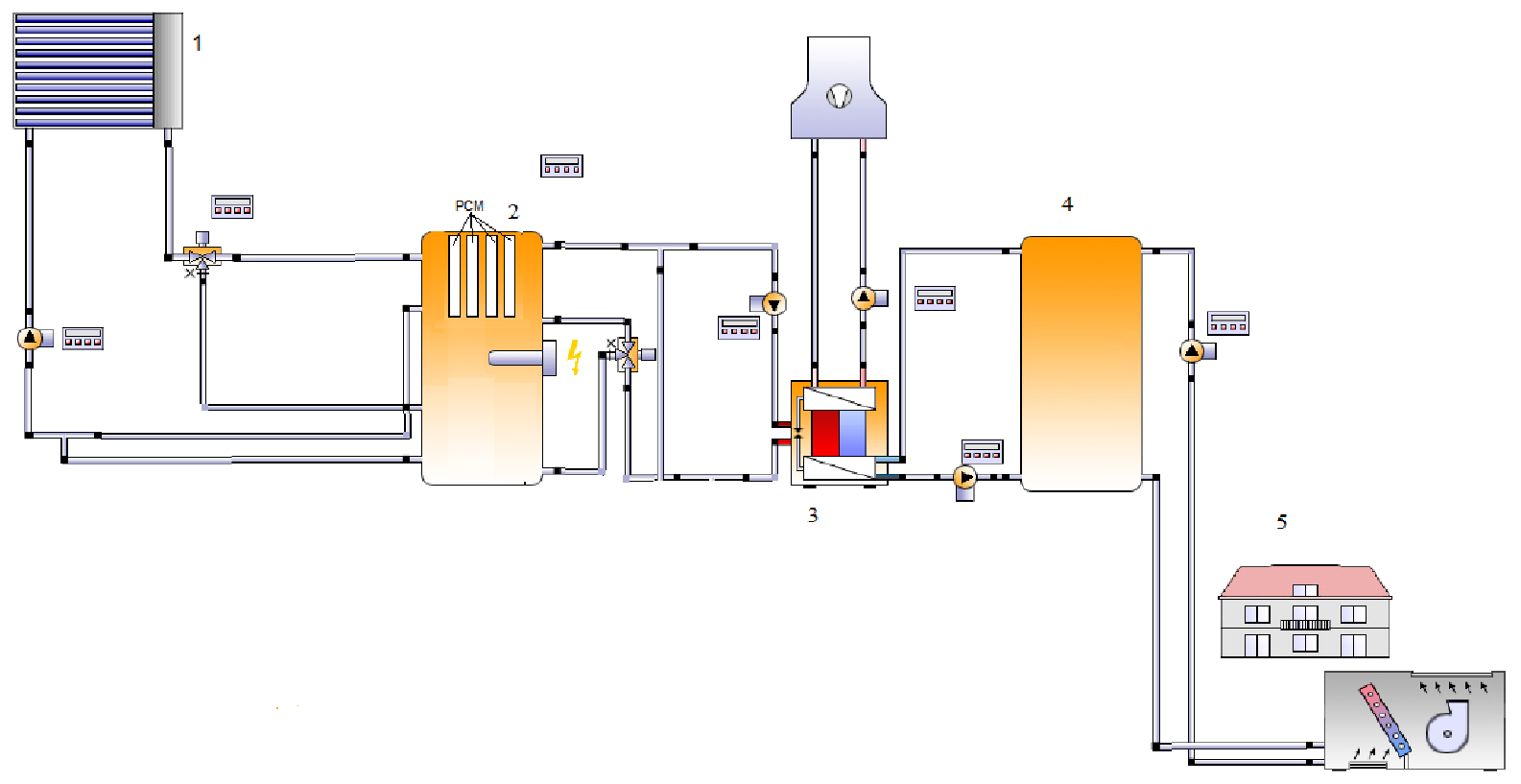

Fig. 2. Scheme of solar cooling system: 1 - solar collector system; 2 - thermal storage tank with PCM tubes; 3 - chiller with cooling tower; 4 - cooling storage; 5 - consumers 
For experiments RUBITHERM ${ }^{\circledR}$ PCM organic materials are used. They use their melting process from solid to liquid (melting and congealing) in order to store and release large amounts of heat in an approximately constant temperature range. Depending on their melting point, a variety of applications at different temperatures can be considered for heat storage. PCM RT70HC material was used with the heat storage capacity $260 \mathrm{~kJ} \cdot \mathrm{kg}^{-1}$, specific heat capacity $2 \mathrm{~kJ} \cdot(\mathrm{kg} \cdot \mathrm{K})^{-1}$, melting area $69-71{ }^{\circ} \mathrm{C}$, heat conductivity (both phases) $0.2 \mathrm{~W} \cdot(\mathrm{m} \cdot \mathrm{K})^{-1}$.

The minimum temperature required to operate the liquid desiccant air conditioning was approximately $55^{\circ} \mathrm{C}$. Water was used as heat transfer fluid and the maximum charging temperature was $95^{\circ} \mathrm{C}$, which is equivalent to $24^{\circ} \mathrm{C}$ temperature difference between the PCM and the heat transfer fluid.

\section{Results and discussion}

For the mathematical equation of the melting process of PCM inside the tube assuming that: the flow is laminar, unsteady, and incompressible and the effect of natural convection during melting is neglected; the thermo-physical properties of the heat transfer fluid and PCMs are independent of the temperature.

The continuity, momentum, and thermal energy equations can be written as the following [9].

Continuity:

$$
\partial_{t}(\rho)+\partial_{i}\left(\rho u_{i}\right)=0
$$

Momentum:

$$
\partial_{t}\left(\rho u_{i}\right)+\left(\rho u_{i} u_{j}\right)=\mu \partial_{j j} u_{i}-\partial_{i} p+p g_{i}+S_{i}
$$

Thermal energy:

$$
\partial_{t}(\rho h)+\partial_{t}(\rho \Delta H)+\partial_{i}(\rho h)=\partial_{i}\left(k \partial_{i} T\right)
$$

where $u_{i}$-fluid velocity;

$\mu$ - dynamic viscosity;

$p$ - pressure;

$g$ - gravity acceleration;

$k$ - thermal conductivity;

$h$ - sensible enthalpy;

$\rho$ - density of PCM (RT70HC).

The sensible enthalpy can be defined as:

$$
h=h_{r e f}+\int_{T_{r e f}}^{T} c p d T
$$

The enthalpy, $\mathrm{H}$, can be defined as:

$$
H=h+\Delta H
$$

where $h_{\text {ref }}-$ reference enthalpy at the reference temperature $T_{r e f}$,

$c p$ - specific heat,

$\Delta H$ - latent heat content that may change between zero (solid) and L (liquid), the latent heat of PCM.

Therefore, the liquid fraction $-\beta$ that happens during the phase change between the solid and liquid state, when the temperature is $T_{1}>T>T_{s}$, can be written as:

$$
\begin{gathered}
\beta=\Delta H / L \\
\beta=\left\{\begin{array}{ccc}
0 & \text { if } & T<T_{s} \\
1 & \text { if } & T>T_{1} \\
\left(T-T_{s}\right) /\left(T_{1}-T_{s}\right) & \text { if } & T_{1}>T>T_{s}
\end{array}\right.
\end{gathered}
$$


In Eq.(2), $S_{i}$ is the Darcy's law damping terms (as source term) that are added to the momentum equation due to the phase change effect on convection. It is defined:

$$
S_{i}=\frac{C(1-\beta)^{2}}{\beta^{3}} u_{i}
$$

The coefficient $\mathrm{C}$ is a mushy zone constant, which is fixed at a value of $10^{5} \mathrm{~kg} \cdot \mathrm{m}^{-3}$ for the present study [12].

Experiments were carried out to compare experimental and numerical data. The experimental data monitoring system consists of K-type thermocouples (measured at $0.5 \%$ accuracy), a data logger, and a computer to measure the temperatures in the tubes with PCM. For numerical study the software FLUENT was used. Colorized contours of solid-liquid front at different time (after 1, 5, 10, 15 and 20 min) are presented of tube with precooling to $1^{\circ} \mathrm{C}$ shown in Fig. 3. It can be seen, that at the beginning a very thin layer of liquid PCM is formed around the hot inner cylinder symmetrically for all arrays. After 5 minutes, this layer expands - solid PCM is more melted in the upper region of the inner cylinder. Thermal conductivity occurs between the hot surface of the inner wall and the cold solid $\mathrm{PCM}$ in the lower region.

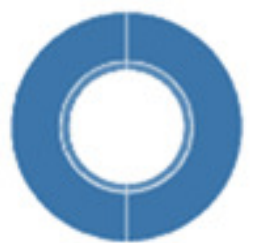

$1 \mathrm{~min}$

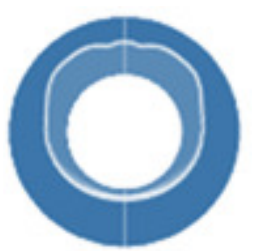

$5 \min$

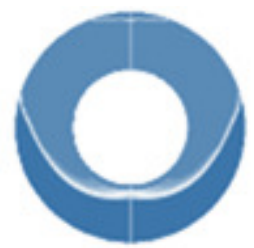

$10 \min$

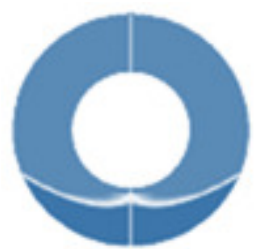

$15 \min$

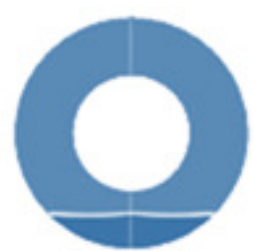

$20 \min$

Fig. 3. Melting phase front for tube (dark blue color: solid PCM)

The average temperature of PCM was $27^{\circ} \mathrm{C}$ when the melting process started, whereas the water temperature was $90{ }^{\circ} \mathrm{C}$, which was maintained in the storage tank by using an electrical heater and a thermostat controller [13]. The mass flow rate of the heat transfer fluid was $8.01 \cdot \mathrm{min}^{-1}$. The melting range of PCM depended on the experimental test, which was between $69^{\circ} \mathrm{C}$ and $71{ }^{\circ} \mathrm{C}$. It should be noted that as the melting area increases, several recirculation regions combine to collect and create the main recirculation region (Fig. 4; $20 \mathrm{~min}$ ). The temperature distribution in the melting area is affected by recirculation. The temperature distribution in the melting area can be seen in Fig. 4 .

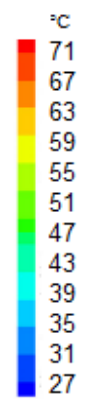

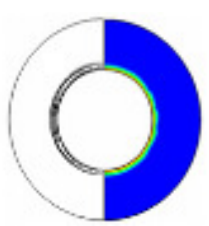

$1 \min$

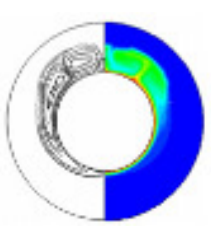

$5 \min$

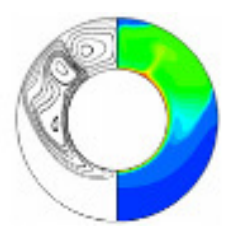

$10 \min$

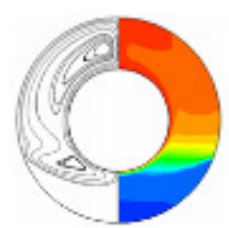

$15 \min$

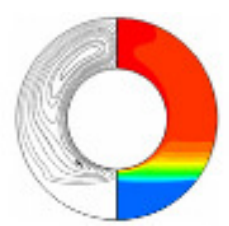

$20 \min$

Fig. 4. Temperature distribution in the melting area

As it is shown in Figure 4, PCM is in a solid aggregate state at $27^{\circ} \mathrm{C}$ and water temperature $90{ }^{\circ} \mathrm{C}$, but on the inner tube side the melting process is going on. After $10 \mathrm{~min}$, PCM turned soft and the temperature rose up to $59^{\circ} \mathrm{C}$.

Full melting occurs at $71^{\circ} \mathrm{C}$ and $20.5 \mathrm{~min}$, respectively. Thus, combined heat conduction and natural heat convection cause to continue linear change of the melting rate.

Experiments were conducted to validate the proposed model. Simulated results agree with the experimental results. 
Hypotheses of the application of latent thermal storage can lead to two important benefits [14]. First, it allows for the rationalization of the heat supply capacity by providing the extra energy during peak hours. Second, it improves the effectiveness of the system when there is a time shift between energy supply and consumption.

The development of the experiments carried out has not yet been effectively included in the solar cooling system. The simulations were carried out for the cooling period only (from May till August). The condition system indoor units are only enabled when the indoor room temperature is higher than $24^{\circ} \mathrm{C}$ during the working days (from Monday to Friday) and working hours (from 9 a.m. to 5 p.m.).

Temperature in the storage tank (from solar collectors, water storage tank, etc.) is controlled by automatic controls. The auxiliary heater turns on, when the temperature of the water in the storage tank falls below the predefined temperature of $90{ }^{\circ} \mathrm{C}$, and switches off only once this condition is satisfied. But when the temperature in the storage tank is within the PCM melting range $\left(59-71^{\circ} \mathrm{C}\right)$, the tubes with PCM return heat to water and in this case the cooling process operates without auxiliary electrical heater.

A lot of simulations were carried out where the influence of the design parameters of the solar cooling system with PCM thermal storage and without it were analysed in terms of system efficiency, with the scope of finding a near optimal system design for the Latvian climate.

Based on the results of simulations, it was concluded that using of the modified storage tank, the energy produced by the auxiliary heater dramatically reduced, because the storage tank maintains the heat carrier temperature needed for SCS operation for longer period. Given that, heat surpluses are used for DHW demand. It must be added that the results of the modified storage tank simulation show significant results in order to provide stable operation of the solar collector field and compensate short term variation of the solar radiation (e.g. cloudy hours) [14]. It is concluded that: auxiliary heater turn on times decreased by $21 \%$ compared to SCS without the modified storage tank, it can be explained by more stable heat maintenance, which will reduce the electricity consumption and increase the SCS lifetime.

The total coefficient of performance (COP) of the existing solar cooling system was close to 4.8, and during the year it varies from 4.6 to 4.9 by month [15]. Using the PCM storage tank, COP on average increased by about $3 \%$ compared COP of SCS without the PCM storage tank.

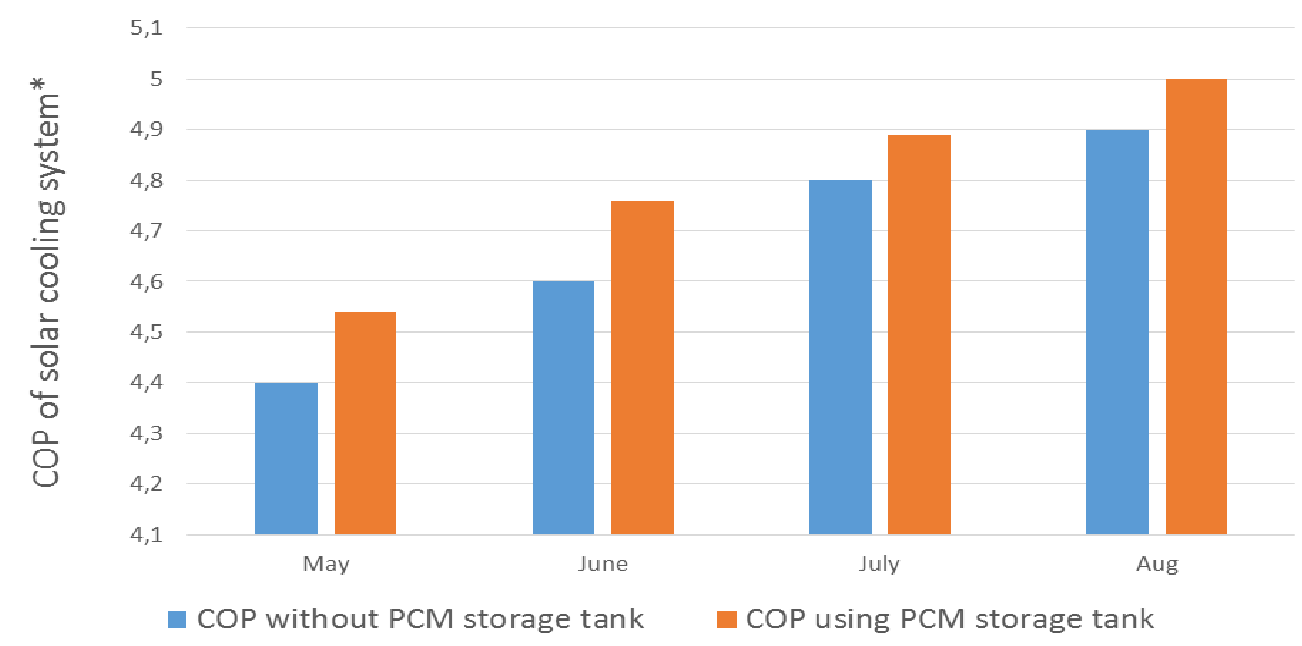

Fig. 5. COP of solar cooling system in northernmost latitudes (*in northernmost latitudes)

\section{Conclusions}

In this work, a software-based dynamic model was designed to evaluate the design efficiency of a solar-driven cooling system with an integrated PCM thermal energy storage device. A case study was conducted to analyze the air conditioning system design options of $80 \mathrm{~m}^{3}$ office rooms (4 rooms) located in Riga, Latvia during summer. A parametric study was performed including the modified storage tank with PCM and without the modified storage tank. Based on the results of the case study, the following major conclusions can be drawn: 
1. Applying latent heat storage with PCM is highly recommended for solar cooling. The application of PCM contributes to improve the cooling COP ratio values.

2. The application of PCM leads to more stable system operation when compared to a system with no PCM thermal energy storage.

From the storage tank (cylindrical vertical tubes filled with PCM configuration, quantity and position) design point of view, the effect of PCM induced motion on the heat transfer coefficient requires further study. Another advantage of using PCMs is that it is possible to reduce the size of the tank due to the higher thermal energy storage density.

\section{References}

[1] Lazzarin R. The 34th Informatory Note on Refrigeration Technologies. Solar Cooling. 2017, 21 p.

[2] Mugnier D., Jakob U. Status of solar cooling in the World. Markets and available products. WIREs. Energy Environment, vol. 4 (3), 2015, pp. 229-234.

[3] Jakob U. Solar air-conditioning in Europe. Chinese Solar Cooling Conference, Shanghai Jiao Tong University, China, 27.03.2015.

[4] Pintaldi S., Perfumo C., Sethuvenkatraman S., White S., Rosengarten G. A review of thermal energy storage technologies and control approaches for solar cooling. Renewable and Sustainable Energy Reviews, vol. 41, January 2015, pp. 975-995.

[5] Gasia J., Diriken J., Bourke M. et al. Comparative study of the thermal performance of four different shell-and-tube heat exchangers used as latent heat thermal energy storage systems, Renewable Energy, 114 (2017), pp. 934-944.

[6] Al-Abidi A.A., Mat S.B., Sopian K., Sulaiman M.Y., Mohammad A.T.. Internal and external fin heat transfer enhancement technique for latent heat thermal energy storage in triplex tube heat exchangers. Appl. Therm. Eng., vol. 53 (1) (2013), pp. 147-156.

[7] Pintaldi S., Perfumo C, Sethuvenkatraman S., White S., Rosengarten G.. A review of thermal energy storage technologies and control approaches for solar cooling. Renewable and Sustainable Energy Reviews, vol. 41(2015), pp. 975-995.

[8] Velraj R., Seeniraj R.V., Hafner B., Faber C., Schwarzer K. Experimental analysis and numerical modelling of inward solidification on a finned vertical tube for a latent heat storage unit. Solar Energy, vol. 60 (1997), pp. 281-290.

[9] Darzi A.R., Farhadi M., Sedighi K. Numerical study of melting inside concentric and eccentric horizontal annulus. Applied Mathematical Modelling, vol. 36 (2012), pp. 4080-4086.

[10] Shipkovs P., Snegirjovs A., Shipkovs J., Kashkarova G., Lebedeva K., Migla L.. Solar Thermal Cooling on the Northernmost Latitudes, Energy Procedia, vol. 70, 2015, pp. 510-5173

[11]Lacroix M. Numerical simulation of a shell-and-tube latent heat thermal energy storage unit. Solar Energy 1993; vol. 50, pp. 357-367.

[12]Darzi A.R., Farhadi M., Sedighi K. Numerical study of melting inside concentric and eccentric horizontal annulus. Applied Mathematical Modelling, Volume 36, Issue 9 (2012), pp. 4080-4086.

[13] Al-Abidi A.A., Mat S., Sopian K., Sulaiman M. Y., Mohammad A.T. Internal and external fin heat transfer enhancement technique for latent heat thermal energy storage in triplex tube heat exchangers. Applied Thermal Engineering, Volume 53, Issue 129 (2013), pp. 147-156.

[14] Allouche Y., Varga S., Bouden C., Oliveira A.C. "Dynamic simulation of an integrated solardriven ejector based air conditioning system with PCM cold storage", Applied Energy, Volume 190 (2017), pp. 600-611.

[15] Shipkovs P., Snegirjovs A., Shipkovs J., Kashkarova G., Lebedeva K., Migla L.. "Solar thermal cooling on the northernmost latitudes". International Conference on Solar Heating and Cooling for Buildings and Industry, SHC 2014. October 13-15, 2014. Beijing, China. Energy Procedia Volume 70, May 2015, pp. 510-517. 